\title{
TU/e EmonOWEN

\section{Detecting patients with PMI post-CABG based on cardiac troponin-T profiles: A latent class mixed modeling approach}

Citation for published version (APA):

Deneer, R., van Boxtel, A. G. M., Boer, A-K., Hamad, M. A. S., van Riel, N. A. W., \& Scharnhorst, V. (2020). Detecting patients with PMI post-CABG based on cardiac troponin-T profiles: A latent class mixed modeling approach. Clinica Chimica Acta, 504, 23-29. https://doi.org/10.1016/j.cca.2020.01.025

\section{Document license:}

TAVERNE

DOI:

10.1016/j.cca.2020.01.025

Document status and date:

Published: 01/05/2020

\section{Document Version:}

Publisher's PDF, also known as Version of Record (includes final page, issue and volume numbers)

\section{Please check the document version of this publication:}

- A submitted manuscript is the version of the article upon submission and before peer-review. There can be important differences between the submitted version and the official published version of record. People interested in the research are advised to contact the author for the final version of the publication, or visit the $\mathrm{DOI}$ to the publisher's website.

- The final author version and the galley proof are versions of the publication after peer review.

- The final published version features the final layout of the paper including the volume, issue and page numbers.

Link to publication

\section{General rights}

Copyright and moral rights for the publications made accessible in the public portal are retained by the authors and/or other copyright owners and it is a condition of accessing publications that users recognise and abide by the legal requirements associated with these rights.

- Users may download and print one copy of any publication from the public portal for the purpose of private study or research.

- You may not further distribute the material or use it for any profit-making activity or commercial gain

- You may freely distribute the URL identifying the publication in the public portal.

If the publication is distributed under the terms of Article 25fa of the Dutch Copyright Act, indicated by the "Taverne" license above, please follow below link for the End User Agreement:

www.tue.nl/taverne

Take down policy

If you believe that this document breaches copyright please contact us at:

openaccess@tue.nl

providing details and we will investigate your claim. 


\title{
Detecting patients with PMI post-CABG based on cardiac troponin-T profiles: A latent class mixed modeling approach
}

\author{
Ruben Deneer ${ }^{\mathrm{a}, \mathrm{b}, *}$, Astrid.G.M. van Boxtel ${ }^{\mathrm{c}}$, Arjen-Kars Boer ${ }^{\mathrm{a}}$, Mohamed A. Soliman Hamad ${ }^{\mathrm{c}}$, \\ Natal A.W. van Riel ${ }^{\mathrm{b}, \mathrm{d}}$, Volkher Scharnhorst ${ }^{\mathrm{a}, \mathrm{b}}$ \\ ${ }^{\text {a }}$ Clinical Laboratory, Catharina Hospital Eindhoven, The Netherlands \\ ${ }^{\mathrm{b}}$ Department of Biomedical Engineering, Eindhoven University of Technology, The Netherlands \\ ${ }^{\mathrm{c}}$ Department of Cardiothoracic Surgery, Catharina Hospital Eindhoven, The Netherlands \\ ${ }^{\mathrm{d}}$ Department of Vascular Medicine, Amsterdam University Medical Centers, The Netherlands
}

\section{A R T I C L E I N F O}

\section{Keywords:}

Coronary artery bypass grafting

Perioperative myocardial infarction

Cardiac troponin

Serial measurements

Profiles

Kinetics

Unsupervised statistical learning

Latent class linear mixed models

Growth mixture models

\begin{abstract}
A B S T R A C T
Background: Diagnosis of perioperative myocardial infarction (PMI) after coronary artery bypass grafting (CABG) is fraught with complexity since it is primarily based on a single cut-off value for cardiac troponin (cTn) that is exceeded in over $90 \%$ of CABG patients, including non-PMI patients. In this study we applied an unsupervised statistical modeling approach to uncover clinically relevant cTn release profiles post-CABG, including PMI, and used this to improve diagnostic accuracy of PMI.

Methods: In 624 patients that underwent CABG, cTnT concentration was serially measured up to 24 h post aortic cross clamping. 2857 cTnT measurements were available to fit latent class linear mixed models (LCMMs).

Results: Four classes were found, described by: normal, high, low and rising cTnT release profiles. With the clinical diagnosis of PMI as golden standard, the rising profile had a diagnostic accuracy of $97 \%$, compared to $83 \%$ for an optimally chosen cut-off and $21 \%$ for the guideline recommended cut-off value.

Conclusion: Clinically relevant subgroups, including patients with PMI, can be uncovered using serially measured cTnT and a LCMM. The LCMM showed superior diagnostic accuracy of PMI. A rising cTnT profile is potentially a better criterion than a single cut-off value in diagnosing PMI post-CABG.
\end{abstract}

\section{Introduction}

Coronary artery bypass grafting (CABG) surgery is an effective procedure to treat ischemic heart disease. Although the safety of CABG surgery is well-established, the procedure is nevertheless associated with a risk of perioperative and postoperative mortality and morbidity. Elevation of cardiac biomarkers such as creatine kinase and cardiac troponin (cTn) is common following CABG surgery and reflects perioperative myocardial damage $[1,2]$. Even small enzyme elevations post$\mathrm{CABG}$ are predictive of long-term prognosis and there is a graded association of elevation with outcome [1]. Perioperative myocardial damage can be ascribed to multiple causes, including direct trauma from surgical handling, inadequate myocardial protection during cardiopulmonary bypass or perioperative myocardial infarction (PMI) [3].
In CABG surgery, PMI is a complication that adversely affects the prognosis of the patient [3]. Incidence of PMI varies depending on the diagnostic criteria and patient population $[3,4]$. Some studies report incidence rates up to $30 \%$, though an average incidence of $3.9 \%$ established in a large systematic review seems more realistic [4]. The fourth universal definition of myocardial infarction (MI) arbitrarily defines a CABG-related PMI (Type 5) as elevation of cardiac troponin (cTn) values $>10$ times the 99th percentile upper reference limit (URL) in patients with normal baseline values during the first $48 \mathrm{~h}$ following CABG surgery, combined with other clinical or echocardiographic evidence [5].

However, the current definition has its limitations. The diagnostic cutoff value of cTn $>10 \times$ URL is arbitrarily defined and occurs in over $90 \%$ of all patients undergoing CABG surgery $[1,6-8]$. As a result,

Abbreviations: CABG, coronary artery bypass grafting; cTn, cardiac troponin; PMI, perioperative myocardial infarction; MI, myocardial infarction; URL, upper reference limit; OPCAB, off-pump coronary artery bypass grafting; LCMM, latent class linear mixed model; XC, aortic cross clamping; ECG, electrocardiogram; BIC, bayesian information criteria; PPV, positive predictive value; NPV, Negative predictive value; ICU, intensive care unit; LoS, length of stay; EHR, electronic health record

* Corresponding author at: Michelangelolaan 2, 5623 EJ Eindhoven, The Netherlands.

E-mail address: ruben.deneer@catharinaziekenhuis.nl (R. Deneer). 
even small degrees of myocardial damage may lead to additional diagnostic procedures and subsequent clinical care pathways [9]. Alternatively, isolated elevations of cardiac biomarkers, which could be prognostically significant, are ignored in the absence of other evidence.

Several studies have focused on the release profile (or kinetics) of cTn post-CABG, arguing that insight in the normal postoperative release profile can aid clinicians in recognizing patients with PMI and that timing of the peak is relevant when applying cut-off values [10-12]. Aside from the normal post-operative CABG cTn release profile, studies describe profiles for off-pump CABG (OPCAB) surgery $[10,11,13]$ and surgeries complicated by PMI [10-12,14-17]. While these studies demonstrate the variability in cTn release profiles and their value in recognizing PMI, they a priori define subgroups based on clinical characteristics or outcomes and subsequently evaluate cTn profiles. An alternative, assumption-free, approach is to group patients according to cTn release profiles and $a$ posteriori evaluate the clinical characteristics and outcomes of each subgroup.

In this study we used an unsupervised statistical learning approach to identify subgroups of patients without using any information other than cTnT release profiles post-CABG. To achieve this we used a statistical modeling technique called latent class linear mixed models (LCMMs) [18].

Our first aim was to fit a LCMM to data from a cohort of CABG patients where cTn was serially sampled post-operatively. From this model, we investigated the mean cTn release profiles of the uncovered classes and analyzed the subgroups of patients assigned to the classes based on clinical characteristics and outcomes, including PMI. Finally, the added value of the LCMM and serial cTn sampling in diagnosing PMI was determined.

\section{Materials and methods}

\subsection{Patient population}

This study was a prospective observational cohort study and all patients who underwent CABG surgery at the Catharina Hospital in Eindhoven between February 2013 and February 2014 were included in this study $(\mathrm{N}=1028)$. Exclusion criteria were patients who underwent CABG with concomitant surgery. If patients underwent a reoperation during the inclusion period, only the first operation was included in the analysis. Blood samples for this study were residual samples obtained during routine withdrawal. Primary endpoints were cTnT profile after uncomplicated cardiac surgery, cTnT profile after cardiac surgery complicated by PMI and short/long-term mortality. Patients with missing data that had either (i) none or only one cTn measurement ( $\mathrm{N}=123$ ), or (ii) where the aortic cross clamping (XC) time was not registered $(\mathrm{N}=4)$, were excluded. Patients were also excluded if there was reasonable doubt whether the labeling of tubes was performed correctly, i.e. a $>28 \mathrm{ng} / \mathrm{L}$ ( $>2 \times$ URL) decrease followed by $>28$ $\mathrm{ng} / \mathrm{L}$ increase during the first $5 \mathrm{~h}$ post-CABG $(\mathrm{N}=27)$.

\section{2. $c T n T$ measurements}

Arterial blood samples were obtained preoperatively ( $\leq 2 \mathrm{~h}$ before surgery) and at $1.5 \mathrm{~h}, 2 \mathrm{~h}, 6 \mathrm{~h}$ and $12-24 \mathrm{~h}$ post XC. If the procedure was performed as an OPCAB, the positioning of the mechanical stabilization device was taken as reference point of time. Samples were collected in BD Vacutainer ${ }^{\circledR}$ heparin tubes and immediately after withdrawal assayed for $\mathrm{cTnT}$ concentration using a high-sensitive $\mathrm{cTnT}$ Immunoassay from Roche Diagnostics Corporation on a Roche Elecsys ${ }^{\circledR}$ platform. The Roche hs-cTnT assay has a $10 \%$ imprecision at $13 \mathrm{ng} / \mathrm{L}$ with a 99th percentile URL of $14 \mathrm{ng} / \mathrm{L}$.

\subsection{PMI diagnosis}

At the time this study was performed, diagnosis of PMI in our institution was based on elevation of ASAT activity. PMI was registered as a complication if ASAT activity was > $100 \mathrm{U} / \mathrm{L}$ combined with (1) new $\mathrm{Q}$ waves on an electrocardiogram (ECG) or new left bundle branch block; or (2) angiographic evidence of graft or native coronary artery occlusion; or (3) echocardiographic imaging evidence of new regional wall motion abnormality or new loss of viable myocardium.

\subsection{Data collection and storage}

Patient data was collected prospectively in the database of the department of cardiac surgery of our institution. These data included demographic information, risk factors, and complications. cTnT results were extracted from the laboratory information system. Mortality data was obtained from the municipal personal records database. All study data was merged and stored in a study database, see Appendix A for the structure of the data.

\subsection{Model fitting}

Linear mixed models $[19,20]$ provide a flexible method to analyze longitudinal data since they incorporate between- and within-patient variability, can handle irregularly sampled and missing data (under the missing at random assumption). However, linear mixed models assume that the underlying population is homogenous and can be described at the population level by a unique profile. If different subpopulations exist within the total population, these have to be explicitly specified. Latent class linear mixed models (LCMMs) assume that the population is heterogeneous and composed of latent classes of subjects, characterized by mean profiles of trajectories $[18,21]$. LCMMs are also referred to as growth mixture models. After the LCMM is fitted, a posterior classification can be made which calculates the probability that each subject belongs to each of the latent classes.

The LCMM consisted of a linear mixed model representing $\log _{10}$ transformed cTnT profiles over time and a multinomial logistic regression model representing (latent) class membership. In the linear mixed model the fixed and random effects were modeled with natural cubic splines since cTnT profiles were expected to be highly nonlinear. Splines are preferred to polynomials due to their local nature and better numerical properties [22]. No predictors were included in the multinomial logistic regression model so class membership was not based on any patient characteristics or outcomes. The LCMM was fitted using R version 3.6.1 [23] and the lcmm package version 1.8.1 [18]. A series of LCMMs were fitted, consisting of an increasing number of latent classes. Since it is known that LCMMs can converge to local maxima [18], each LCMM was fitted 100 times with randomly chosen starting values to ensure that each model converged to a global maximum. The number of latent classes was increased until the Bayesian information criteria (BIC) $[18,24]$ started increasing with the addition of an extra latent class. The selection of the best model was based on (i) the BIC and $\triangle \mathrm{BIC}$, (ii) the posterior classification table and (iii) clinical relevance $[18,25]$. Mathematical formulation, model selection procedures and $\mathrm{R}$ code used to fit the model can be found in Appendix A.

\subsection{Post-hoc analysis}

After selecting a LCMM, classes were given names based on the evolution of the mean cTnT. Class membership probabilities were calculated and each patient was a posteriori assigned to the class that corresponded to the highest probability. The differences between classes were analyzed with respect to patient characteristics, procedural characteristics and outcomes. If there were statistically significant $(\mathrm{p}<0.05)$ differences between classes for a particular variable, posthoc tests were used to compare which particular pair(s) of classes differed. Tukey's test was used for continuous variables, Dunn's test for non-normal continuous variables and pairwise Fisher tests for categorical variables. The Holm-Bonferroni method was used to adjust p- 


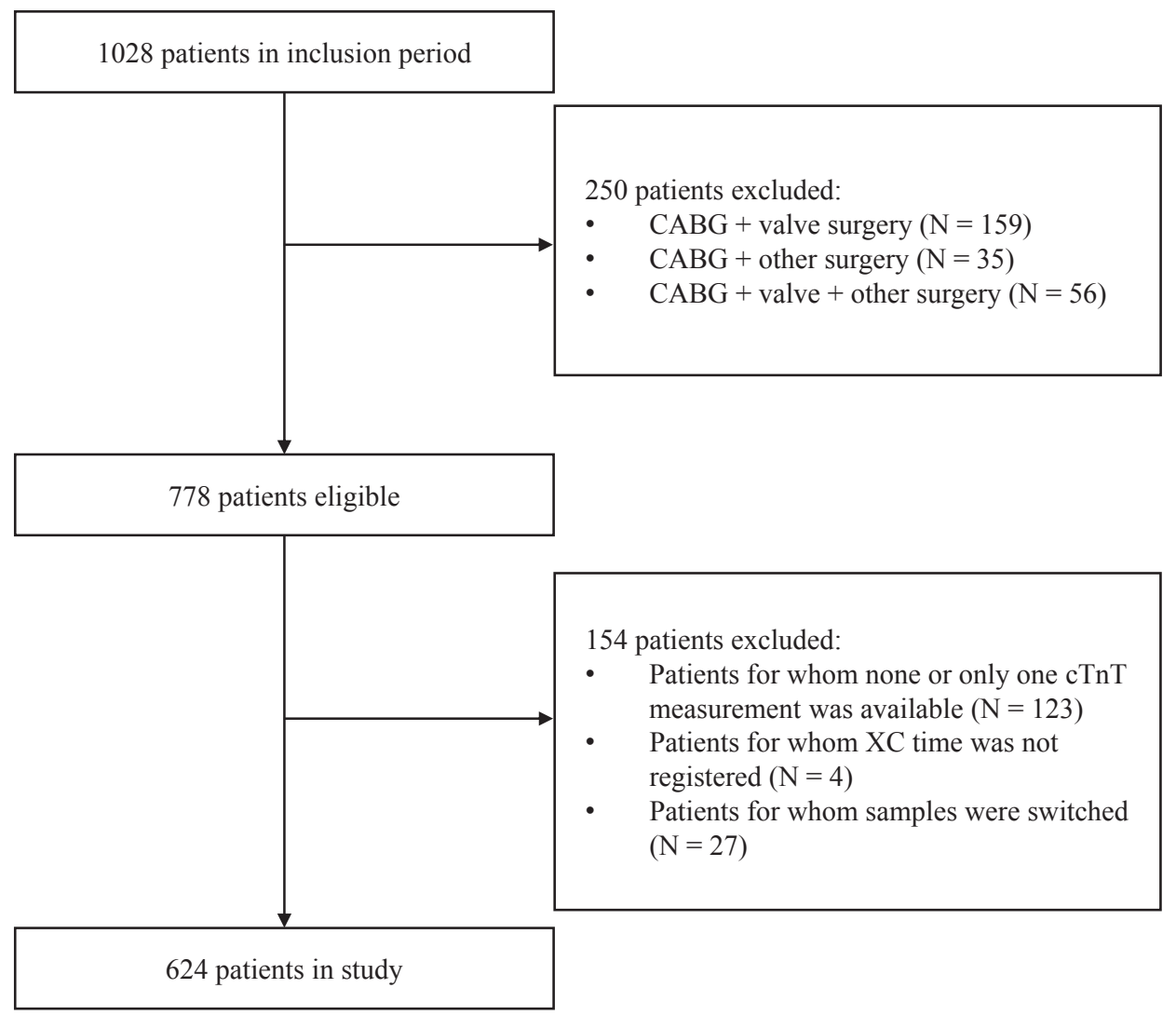

Fig. 1. Inclusion flowchart. Flowchart describing inclusion of patients.

values for multiple comparisons.

Patients that were assigned to a rising profile class (i.e. cTnT still rising at $24 \mathrm{~h}$ post XC) were considered positive for PMI by the LCMM. The classification of the LCMM was compared to the clinical diagnosis of PMI in terms of sensitivity, specificity, positive predictive value (PPV), negative predictive value (NPV) and accuracy using the caret package [26]. This was also done for the guideline definition [5] and for an optimally chosen cutoff. The optimally chosen cutoff was based on the Youden index [27] of the receiver operating characteristic (ROC) curve of the maximum cTnT value within $24 \mathrm{~h}$ post XC and the clinical diagnosis of PMI. Since a LCMM cannot be directly implemented in the clinic, we also assessed the added value of the LCMM in the clinical practice by defining a simple criterion based on visual inspection of the mean profiles.

\section{Results}

\subsection{Study population}

In total, 1028 patients were included in the study, see Fig. 1. Patients with concomitant procedures were excluded, leaving 778 patient that underwent CABG without combined surgery. Of these 778 patients, some patients had missing or incorrect data with respect to the cTnT measurements, the XC time or the labelling of pre- and post-operative samples. After excluding patients with missing or erroneous data, a total of 624 patients remained in the analysis. Patient characteristics and outcomes are summarized in Table 1.

\subsection{Latent class mixed model}

LCMMs were fitted with up to 6 latent classes. The BIC of the LCMMs decreased from 762.80 for a model without latent classes to a minimum of 514.86 for a model with 5 latent classes. The model with 4 latent classes (BIC $=518.86$ ) was chosen as the final model, given the small decrease in BIC (-4.00) when going from 4 to 5 latent classes (reflecting modest evidence for a fifth class [28]) and higher discriminative ability. For more details regarding model selection, see Appendix A. In Fig. 2A the estimated mean profile of each of the four latent classes in the final model is plotted. Patients were assigned to the class with the highest posterior probability. The individual profiles of patients assigned to each of the four classes are shown in Fig. 2B. Classes were labelled according to the shape of the profile. The "normal profile" class $(\mathrm{N}=523,83.8 \%)$ contains the majority of patients and shows a typical cTnT profile post-CABG: a sharp increase in cTnT with a peak around $4-5 \mathrm{~h}$ post-XC, representing periprocedural myocardial damage, followed by a slow steady decline. The "rising profile" class ( $N=29,4.6 \%$ ) shows an initial sharp increase similar to the "normal profile" but where the cTnT concentration continues to rise until the end of the measurement period $(24 \mathrm{~h})$. The "low profile" class $(\mathrm{N}=40$, $6.4 \%$ ) shows a slower increase and a lower peak cTnT than the "normal profile". The "high profile" class $(\mathrm{N}=32,5.1 \%)$ contains patients with an elevated baseline cTnT that peaks around $10 \mathrm{~h}$ post XC and then starts to decline.

\subsection{Latent class characteristics and outcomes}

Patients were assigned to the class with the highest posterior probability and classes were compared based on patient characteristics, procedural characteristics and outcomes in Table 2. Patients in the low profile class almost exclusively underwent OPCAB surgery and were on average younger than patients in the high profile class. Patients in the high or rising profile class had higher surgical risk (i.e. higher EuroSCORE) than patients in the normal or low profile class. This was also reflected by the fact that these patients more often underwent emergency procedures than patients in the normal profile class. Patients in the high or rising profile class had a longer length of stay (LoS) in the 
Table 1

Characteristics of the study population and outcomes.

\begin{tabular}{|c|c|}
\hline & $\mathrm{N}=624$ \\
\hline \multicolumn{2}{|l|}{ Preoperative } \\
\hline Age in years $\uparrow$ & $65.65( \pm 9.68)$ \\
\hline Female gender & $121(19.4 \%)$ \\
\hline Body mass index in $\mathrm{kg} / \mathrm{m}^{2} \dagger$ & $27.63( \pm 4.01)$ \\
\hline Diabetes & $134(21.5 \%)$ \\
\hline Hypertension & $367(58.8 \%)$ \\
\hline Peripheral vascular disease & $65(10.4 \%)$ \\
\hline Previous stroke & $34(5.4 \%)$ \\
\hline \multicolumn{2}{|l|}{ Left-ventricular function } \\
\hline Good & $511(81.9 \%)$ \\
\hline Moderate & $90(14.4 \%)$ \\
\hline Poor & $14(2.2 \%)$ \\
\hline Very poor & $1(0.2 \%)$ \\
\hline Unknown & $8(1.3 \%)$ \\
\hline Additive EuroSCORE + & $3.00[2.00,5.00]$ \\
\hline Prior cardiac surgery & $16(2.6 \%)$ \\
\hline Emergency procedure & $16(2.6 \%)$ \\
\hline Pre-op hemoglobin $(\mathrm{mmol} / \mathrm{L}) \dagger$ & $9.00( \pm 0.88)$ \\
\hline Pre-op creatinine (umol/L) $\leftarrow$ & $88.00[76.00,100.00]$ \\
\hline \multicolumn{2}{|l|}{ Intraoperative } \\
\hline \multicolumn{2}{|l|}{ Intra-aortic balloon pump } \\
\hline No & $616(98.7 \%)$ \\
\hline Pre-op & $2(0.3 \%)$ \\
\hline Per-op & $3(0.5 \%)$ \\
\hline Post-op & $3(0.5 \%)$ \\
\hline Off-pump CABG & $133(21.3 \%)$ \\
\hline Aortic cross-clamp time (min.) $\dagger$ & $45.00[35.00,59.00]$ \\
\hline Cardiopulmonary bypass time (min.) $\dagger$ & $73.00[57.00,90.00]$ \\
\hline \multicolumn{2}{|l|}{ Postoperative } \\
\hline Length of stay on ICU (days) $\doteqdot$ & $1.00[0.00,1.00]$ \\
\hline Length of stay in hospital (days) + & $5.00[4.00,6.00]$ \\
\hline Perioperative myocardial infarction & $23(3.7 \%)$ \\
\hline Required reoperation & $38(6.1 \%)$ \\
\hline Early mortality (30 days) & $4(0.6 \%)$ \\
\hline Late mortality ( 5 years) & $49(7.9 \%)$ \\
\hline \multicolumn{2}{|l|}{ Number of cTnT measurements } \\
\hline 2 & $29(4.6 \%)$ \\
\hline 3 & $45(7.2 \%)$ \\
\hline 4 & $121(19.4 \%)$ \\
\hline 5 & $396(63.5 \%)$ \\
\hline 6 & $31(5.0 \%)$ \\
\hline 7 & $2(0.3 \%)$ \\
\hline
\end{tabular}

CABG = coronary artery bypass grafting; ICU = intensive care unit; $\mathrm{cTnT}=$ cardiac troponin-T; $\dagger$ mean $( \pm \mathrm{SD}) ;+$ median $[\mathrm{IQR}]$.

intensive care unit (ICU) and hospital, than patients in the low or normal profile class. Finally, patients that were assigned to the rising profile class were more often diagnosed with PMI and showed signs of ischemia on an ECG. There were no statistically significant differences between classes in terms of early or late mortality.

\subsection{Latent classes and the diagnosis of PMI}

$55 \%$ of patients in the rising profile class were clinically diagnosed with PMI whereas $98.8 \%$ of patients in any of the other classes were not clinically diagnosed with PMI. Patients that were assigned to the rising profile class were considered positive for PMI. Fig. 3 shows the agreement between the LCMM rising class PMI classification and the clinical diagnosis of PMI in our clinic. For 16 of the 23 patients that had PMI there is agreement between the LCMM and the clinical diagnosis (true/ concordant positives). 5 patients were classified in the normal profile class and 2 patients were classified in the high profile class, in spite of being clinically diagnosed with PMI (false/discordant negatives). 13 patients that were not clinically diagnosed with a PMI were classified in the rising profile class (false/discordant positives), the remaining 599 patients were all not diagnosed with a PMI and did not appear in the rising profile class (true/concordant negatives).

From the mean profiles in Fig. 2A it can be seen that only the PMI class is still rising between 6 and $24 \mathrm{~h}$ post XC. To assess the added value for the clinic, five different methods to classify patients with PMI are compared based on sensitivity, sensitivity, PPV, NPV and accuracy. The results are shown in Table 3. The LCMM approach had the highest accuracy and PPV without sacrificing NPV. The additional criterion that cTnT is rising between 6 and $24 \mathrm{~h}$ post XC improved accuracy compared to the current guideline criterion and an optimally chosen cut-off.

\section{Discussion}

In this study we investigated whether subgroups of patients could be identified based on cTnT release profiles post-CABG, in particular patients with PMI. Our results illustrate that by using a LCMM, subgroups of patients could be identified that show distinctive cTnT profiles without using any prior information other than serial cTnT measurements taken up to $24 \mathrm{~h}$ post XC. Using the model's posterior classification of patients to a rising cTnT profile showed substantially greater accuracy and PPV (without affecting NPV) in diagnosing PMI compared to the guideline criteria.

First, a model with latent classes had a substantially lower BIC than a model without latent classes (518.86 versus 762.80 ), indicating that a model with latent classes is a better fit to the data $[18,25,28]$. In addition to the BIC, the diagonal terms in the posterior classification table were close to $1(0.86,0.89,0.96,0.94)$ reflecting good discriminative ability [18]. While the five class model had slightly lower BIC, the four class model was chosen due to the better discriminative ability. Also, there is substantive theory from literature which validates the choice for a four class model. The low profile class, which contains almost exclusively $\mathrm{OPCAB}$ surgeries, is in agreement with literature describing a delayed and lower peak for OPCAB surgery $[10,11,13]$. The rising profile class is also in agreement literature, describing a PMI profile as having a delayed peak or rise following an earlier peak [10,12,14-17]. To explain the cTnT release profile of patients with PMI, most studies refer to the work from Katus et. al who suggest that early release represents cytosolic troponin from myocytes that are reversible damaged, whereas late release (after one day) represents structural troponin from irreversibly damaged myocytes [29]. The high profile class is not described in literature. This is explained by the fact that most studies exclude patients with emergency procedures or procedures within seven days of a MI, which are most likely patients with elevated baseline cTnT in the high profile class.

The post hoc analysis revealed that the rising profile class consisted of more than half of patients clinically diagnosed with PMI.

There were thirteen discordant positive patients (of 624 in total), i.e. patients that were assigned to the rising profile class but were not clinically diagnosed with PMI. Nine patients had peak ASAT $\leq 100 \mathrm{U} / 1$ and did therefore not meet the ASAT-criterion to be diagnosed with PMI. The electronic health records (EHRs) of the remaining four patients were re-examined by a thoracic surgeon. Three patients had no secondary evidence (ECG or echocardiographic) of PMI and were therefore not diagnosed with PMI, one patient started to develop PMI but re-intervention took place before the final diagnosis was made.

There were seven discordant negative patients, i.e. patients that were clinically diagnosed with PMI but not assigned to the rising profile class. The EHRs of these seven patients were also re-examined by a thoracic surgeon. Five patients did not have elevated cardiac enzymes but were diagnosed with PMI on the basis of a combination of other diagnostic criteria i.e. ECG abnormalities, echocardiographic evidence or hemodynamic instability. Two patients were incorrectly clinically diagnosed with PMI, one patient had pre-operative MI and one patient was mislabeled as positive. Although only mismatched cases were reexamined, the causes of misclassification were mainly due to the ASAT criterion or (lack of) evidence of other clinical or echocardiographic abnormalities. If the two patients that were incorrectly labelled with PMI were re-classified as negative, the sensitivity of the LCMM increased to 0.76 and the specificity to 0.99 . 
A

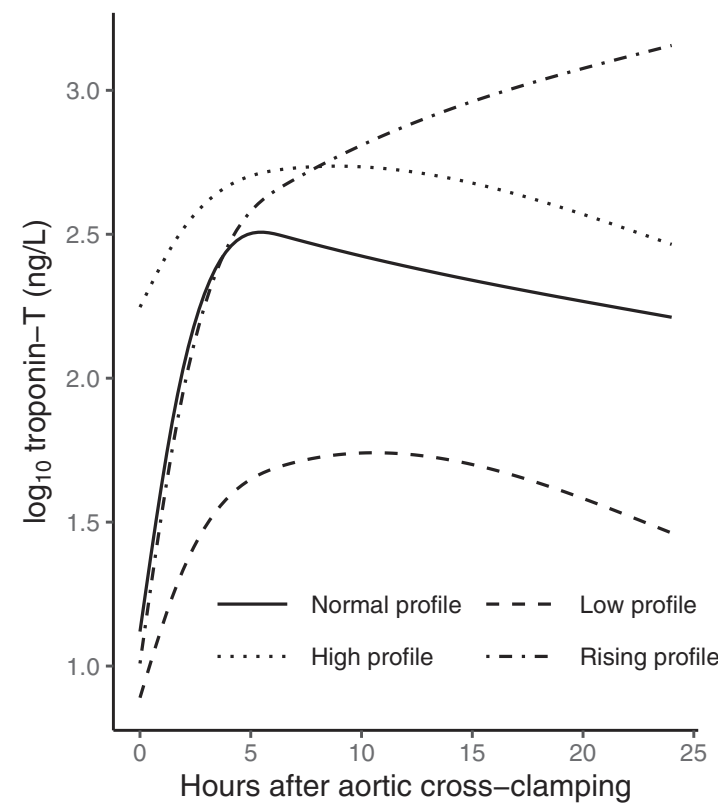

B

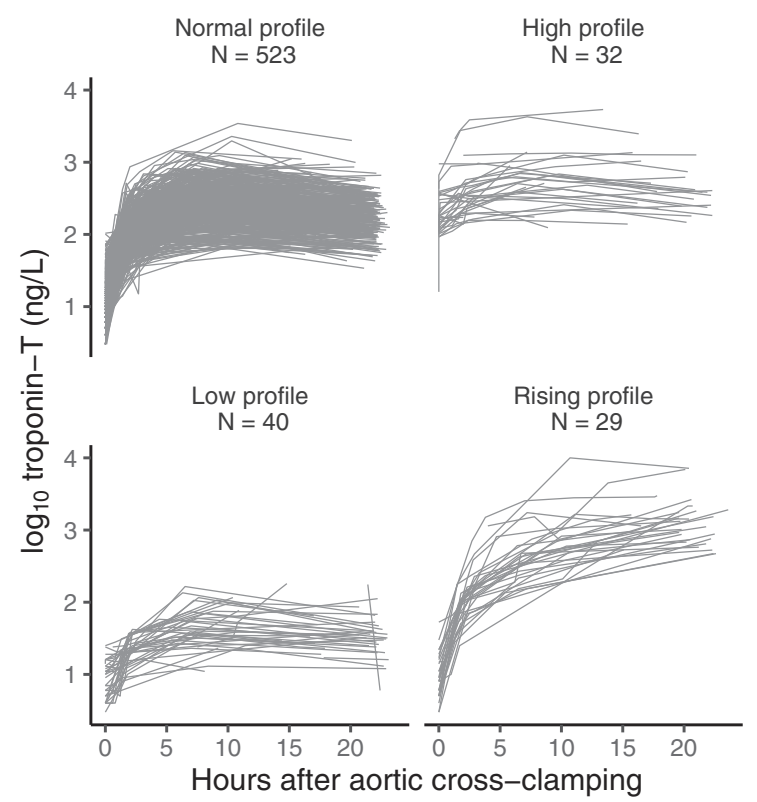

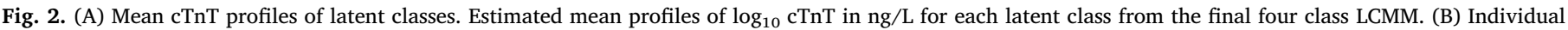

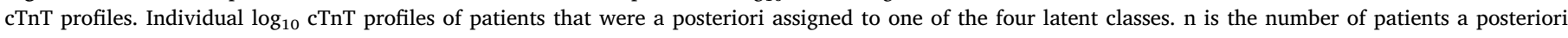
assigned to that class.

That the LCMM is not in perfect agreement with the clinical diagnosis of PMI, is not merely a shortcoming of the model but also of the variation in the diagnosis of PMI. Confirming or denying a diagnosis of PMI may be of secondary importance to the clinical consequences. Although clinical consequences such as major adverse cardiac and cerebrovascular events were not registered in our study, post hoc tests revealed that patients with a rising cTnT profile had a longer LoS in the hospital (Dunn's test p-value: 0.045), a longer LoS on the ICU (Dunn's test p-value: 0.0036 ) and more often had signs of ischemia on an ECG (Fisher's exact test p-value: $<0.001$ ) than patients with a normal cTnT profile. This is in agreement with previous studies who reported associations between elevated post-operative cTnT and prolonged stay on the ICU $[30,31]$.

A limitation of our study is that we did not have samples $>24 \mathrm{~h}$ post XC, therefore we could not determine the timing of the cTnT peak for patients with PMI. Previous studies observed a rising pattern even after $48 \mathrm{~h}[11,14]$. However, non-PMI patients reach their peak between 4 and $12 \mathrm{~h}$ post $\mathrm{XC}$, therefore $24 \mathrm{~h}$ is sufficient to distinguish early versus late peak occurrence. This finding also confirms the potential for early ( $<12 \mathrm{~h}$ post-CABG) cTnT to detect patients at risk for PMI or other adverse events as reported by other studies [31,32].

Another limitation is that the model in its current form is difficult to implement in a prospective manner in the clinic. However, we have demonstrated that information gathered from the estimated mean cTnT profile (that cTnT in patients in the rising class is still rising between 6 and $24 \mathrm{~h}$ post XC) can already improve diagnostic accuracy, both with respect to the guideline and an optimally chosen cutoff. Our approach of visually interpreting estimated mean cTnT profiles does not take any

Table 2

Patient characteristics of latent classes.

\begin{tabular}{|c|c|c|c|c|c|}
\hline & Normal profile & High profile & Low profile & Rising profile & p-value* \\
\hline & $\mathrm{N}=523$ & $\mathrm{~N}=32$ & $\mathrm{~N}=40$ & $\mathrm{~N}=29$ & \\
\hline Age in years $\uparrow$ & $65.8( \pm 9.4)$ & $68.2( \pm 10.6)$ & $61.8( \pm 12.1)$ & $64.6( \pm 8.9)$ & 0.026 \\
\hline Female gender & $97(18.5 \%)$ & $7(21.9 \%)$ & $9(22.5 \%)$ & $8(27.6 \%)$ & 0.602 \\
\hline EuroSCORE + & $3.0[2.0,5.0]$ & $6.0[3.0,7.0]$ & $3.0[1.0,4.0]$ & $3.0[3.0,5.0]$ & $<0.001$ \\
\hline Emergency & $5(1.0 \%)$ & $6(18.8 \%)$ & $2(5.0 \%)$ & $3(10.3 \%)$ & $<0.001$ \\
\hline Off-pump CABG & $81(15.5 \%)$ & $5(15.6 \%)$ & $38(95.0 \%)$ & $9(31.0 \%)$ & $<0.001$ \\
\hline XC time (min.) $\div$ & $45.0[35.0,58.5]$ & $49.0[37.5,58.5]$ & $61.0[60.5,61.5]$ & $59.0[43.0,64.2]$ & 0.071 \\
\hline $\mathrm{CPB}$ time $(\mathrm{min})+$. & $72.0[55.0,88.5]$ & $77.5[64.8,88.0]$ & $106.0[102.5,109.5]$ & $94.0[70.0,99.0]$ & 0.028 \\
\hline Days on ICU + & $1.0[0.0,1.0]$ & $1.0[0.0,2.0]$ & $0.0[0.0,1.0]$ & $2.0[0.0,3.0]$ & $<0.001$ \\
\hline Days in hospital $\nleftarrow$ & $5.0[4.0,6.0]$ & $6.0[4.0,9.0]$ & $4.0[4.0,6.0]$ & $6.0[5.0,7.0]$ & 0.001 \\
\hline PMI & $5(1.0 \%)$ & $2(6.2 \%)$ & $0(0.0 \%)$ & $16(55.2 \%)$ & $<0.001$ \\
\hline ECG conclusion & & & & & $<0.001$ \\
\hline No ischemia & $440(84.1 \%)$ & $25(78.1 \%)$ & $33(82.5 \%)$ & $12(41.4 \%)$ & \\
\hline Possible ischemia & $61(11.7 \%)$ & $6(18.8 \%)$ & $6(15.0 \%)$ & $7(24.1 \%)$ & \\
\hline Definite ischemia & $10(1.9 \%)$ & $0(0.0 \%)$ & $0(0.0 \%)$ & $10(34.5 \%)$ & \\
\hline Inconclusive & $12(2.3 \%)$ & $1(3.1 \%)$ & $1(2.5 \%)$ & $0(0.0 \%)$ & \\
\hline Early mortality & $4(0.8 \%)$ & $0(0.0 \%)$ & $0(0.0 \%)$ & $0(0.0 \%)$ & 0.855 \\
\hline Late mortality & $41(7.8 \%)$ & $4(12.5 \%)$ & $3(7.5 \%)$ & $1(3.4 \%)$ & 0.628 \\
\hline
\end{tabular}

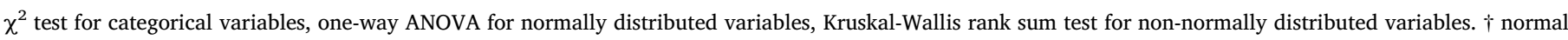

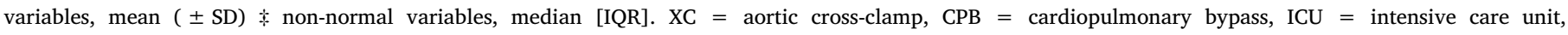
$\mathrm{PMI}=$ perioperative myocardial infarction.

*p-values determines if there are significant differences between classes. 


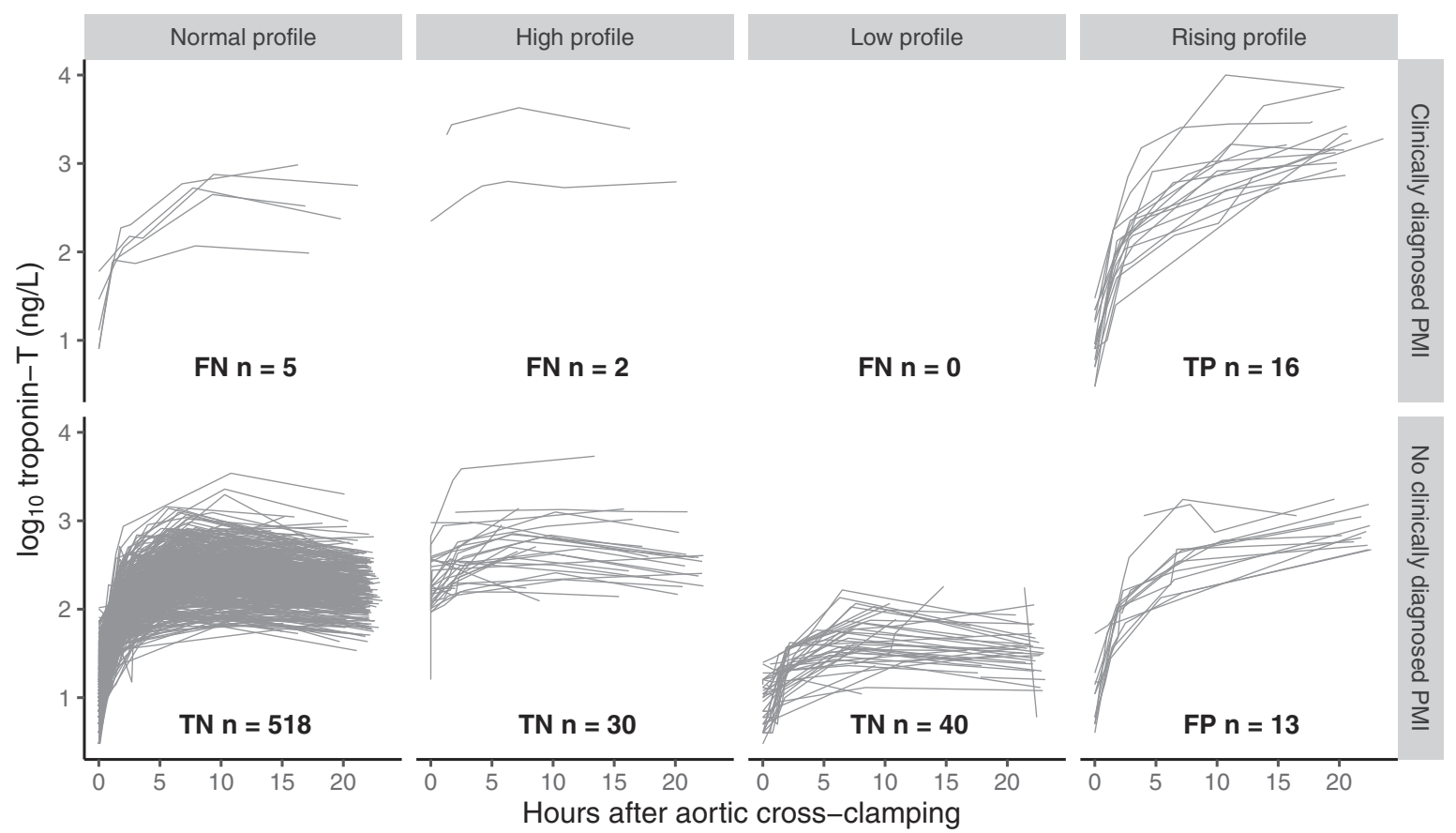

Fig. 3. Confusion matrix plot. Individual $\log _{10}$ cTnT profiles of patients split by clinical diagnosis of PMI (upper row with clinical diagnosis of PMI, bottom row without PMI) and posterior class assignment by the LCMM (normal, high, low and rising profile in each column respectively). TP = true positives; FN = false negatives; $\mathrm{FP}=$ false positives; $\mathrm{TN}=$ true negatives.

Table 3

Sensitivity, specificity, PPV and NPV for different approaches to detecting patients with a PMI.

\begin{tabular}{lccccl}
\hline \multicolumn{1}{c}{ cTnT PMI classification method } & Sens. & Spec. & PPV & NPV & Accuracy \\
\hline Guideline definition & 0.96 & 0.18 & 0.05 & 0.99 & 0.21 \\
Guideline definition \& rising after 6 h & 0.91 & 0.40 & 0.06 & 0.99 & 0.42 \\
Optimal cutoff* & 0.91 & 0.83 & 0.18 & 1.00 & 0.83 \\
Optimal cutoff* \& rising after 6 h & 0.87 & 0.87 & 0.22 & 0.99 & 0.87 \\
LCMM rising class & 0.70 & 0.98 & 0.55 & 0.99 & 0.97 \\
\hline
\end{tabular}

Sens. = sensitivity; spec. $=$ specificity; $\mathrm{PPV}=$ positive predictive value; NPV = negative predictive value, LCMM = latent class linear mixed model.

* The optimal cutoff for cTnT based on the Youden index was $528.5 \mathrm{ng} / \mathrm{L}$.

variability into account and is only a proof of concept. Also, given the multifactorial causes for post-operative cTnT elevation, one can expect differences between centers. Consequently the results obtained from this single center analysis may not be generalizable to other centers.

Finally, although LCMMs do not prove that the found subpopulations actually exist [33] and skepticism of complex statistical models is appropriate, the fit indices combined with substantive theory and high diagnostic accuracy of PMI patients provide strong evidence to assume that the heterogeneity in cTnT release profiles is the result of actual subpopulations instead of other causes of non-normality. We have demonstrated that a statistical model is capable of recognizing clinically relevant subgroups of patients based on cTnT release profiles postCABG and that information from this model can be used to improve the guideline for Type 5 MI. Future studies should be done to determine the optimal sampling time-points of cTnT to detect a rising pattern and the associated improvement compared to a single cut-off value in diagnosing PMI.

\section{Conclusions}

This study has shown that characteristic cTnT release profiles exist post-CABG surgery. These profiles could be uncovered by a LCMM without any prior information other than serial cTnT measurements up to $24 \mathrm{~h}$ post XC. Four classes were discovered that showed a low, high, rising and normal cTnT release profile. Patients were a posteriori assigned to each of one of these classes. The rising profile proved to be predictive for PMI, with higher PPV and accuracy than the guideline recommended cutoff or an optimally chosen cutoff. We argue that a rising cTnT release profile is potentially of greater predictive value for PMI than a single value above or below a cutoff.

\section{CRediT authorship contribution statement}

Ruben Deneer: Conceptualization, Methodology, Software, Formal analysis, Data curation, Writing - original draft, Visualization. Astrid.G.M. van Boxtel: Conceptualization, Investigation, Data curation, Writing - review \& editing. Arjen-Kars Boer: Methodology, Writing - review \& editing, Visualization, Supervision. Mohamed A. Soliman Hamad: Investigation, Writing - review \& editing, Supervision. Natal A.W. van Riel: Methodology, Writing - review \& editing, Supervision. Volkher Scharnhorst: Conceptualization, Resources, Writing - review \& editing, Supervision, Project administration.

\section{Appendix A. Supplementary material}

Supplementary data to this article can be found online at https:// doi.org/10.1016/j.cca.2020.01.025.

\section{References}

[1] M.J. Domanski, K. Mahaffey, V. Hasselblad, S.J. Brener, P.K. Smith, G. Hillis, M. Engoren, J.H. Alexander, J.H. Levy, B.R. Chaitman, S. Broderick, M.J. Mack, K.S. Pieper, M.E. Farkouh, Association of myocardial enzyme elevation and survival following coronary artery bypass graft surgery, JAMA 305 (2011) 585-591, https:// doi.org/10.1001/jama.2011.99.

[2] J.L. Januzzi, K. Lewandrowski, T.E. MacGillivray, J.B. Newell, S. Kathiresan, S.J. Servoss, E. Lee-Lewandrowski, A comparison of cardiac troponin T and creatine kinase-MB for patient evaluation after cardiac surgery, J. Am. Coll. Cardiol. 39 (2002) 1518-1523, https://doi.org/10.1016/S0735-1097(02)01789-8.

[3] J.M. Yau, J.H. Alexander, G. Hafley, K.W. Mahaffey, M.J. Mack, N. Kouchoukos, A. Goyal, E.D. Peterson, C.M. Gibson, R.M. Califf, R.A. Harrington, T.B. Ferguson, Impact of Perioperative myocardial infarction on angiographic and clinical 
outcomes following coronary artery bypass grafting (from PRoject of Ex-vivo Vein graft ENgineering via transfection [Prevent] IV), Am. J. Cardiol. 102 (2008) 546-551, https://doi.org/10.1016/j.amjcard.2008.04.069.

[4] L. Nalysnyk, K. Fahrbach, M.W. Reynolds, S.Z. Zhao, S. Ross, Adverse events in coronary artery bypass graft (CABG) trials: a systematic review and analysis, Heart 89 (2003) 767-772, https://doi.org/10.1136/heart.89.7.767.

[5] Kristian Thygesen, Joseph S. Alpert, Allan S. Jaffe, Bernard R. Chaitman, Jeroen J. Bax, David A. Morrow, Harvey D. White, Fourth universal definition of myocardial infarction (2018), J. Am. Coll. Cardiol. 72 (18) (2018) 2231-2264, https:// doi.org/10.1016/j.jacc.2018.08.1038.

[6] T.K. Wang, R.A. Stewart, T. Ramanathan, N. Kang, G. Gamble, H.D. White, Diagnosis of MI after CABG with high-sensitivity troponin T and new ECG or echocardiogram changes: relationship with mortality and validation of the Universal Definition of MI, Eur. Heart J.: Acute Cardiovas. Care. 2 (2013) 323-333, https://doi.org/10.1177/2048872613496941.

[7] J.D. Muehlschlegel, T.E. Perry, K.-Y. Liu, L. Nascimben, A.A. Fox, C.D. Collard, E.G. Avery, S.F. Aranki, M.N. D'Ambra, S.K. Shernan, S.C. Body, Troponin is superior to electrocardiogram and creatinine kinase MB for predicting clinically significant myocardial injury after coronary artery bypass grafting, Eur. Heart J. 30 (2009) 1574-1583, https://doi.org/10.1093/eurheartj/ehp134.

[8] A.A. Mohammed, A.K. Agnihotri, R.R. van Kimmenade, A. Martinez-Rumayor, S.M. Green, R. Quiroz, J.L. Januzzi, Prospective, comprehensive assessment of cardiac troponin $\mathrm{T}$ testing after coronary artery bypass graft surgery, Circulation 120 (2009) 843-850, https://doi.org/10.1161/CIRCULATIONAHA.108.837278.

[9] I.D. Moussa, L.W. Klein, B. Shah, R. Mehran, M.J. Mack, E.S. Brilakis, J.P. Reilly, G. Zoghbi, E. Holper, G.W. Stone, Consideration of a new definition of clinically relevant myocardial infarction after coronary revascularization: an expert consensus document from the society for cardiovascular angiography and interventions (SCAI), J. Am. Coll. Cardiol. 62 (2013) 1563-1570, https://doi.org/10.1016/j.jacc. 2013.08.720.

[10] W. Ge, C. Gu, C. Chen, W. Chen, Z. Cang, Y. Wang, C. Shi, Y. Zhang, High-sensitivity troponin $\mathrm{T}$ release profile in off-pump coronary artery bypass grafting patients with normal postoperative course, BMC Cardiovasc. Dis. 18 (2018) 157, https://doi.org/ 10.1186/s12872-018-0893-2.

[11] P.L. Markman, J.-P. Tantiongco, J.S. Bennetts, R.A. Baker, High-sensitivity troponin release profile after cardiac surgery, Heart Lung Circul. 26 (2017) 833-839, https:// doi.org/10.1016/j.hlc.2016.09.017.

[12] H.T. Tevaearai Stahel, P.D. Do, J.B. Klaus, B. Gahl, D. Locca, V. Göber, T.P. Carrel, Clinical Relevance of Troponin T Profile Following Cardiac Surgery, Front Cardiovasc Med. 5 (2018) 182. https://doi.org/10.3389/fcvm.2018.00182

[13] A. Wittock, N. De Mey, K. De Decker, I. Brandt, C. Van Mieghem, G. Cammu, L. Foubert, High-sensitive cardiac troponins in patients undergoing cardiac surgery: friend or foe? ICMx. 3 (2015) A952, https://doi.org/10.1186/2197-425X-3-S1A952.

[14] M. Carrier, M. Pellerin, L.P. Perrault, B.C. Solymoss, L.C. Pelletier, Troponin levels in patients with myocardial infarction after coronary artery bypass grafting, Ann. Thoracic Sur. 69 (2000) 435-440, https://doi.org/10.1016/S0003-4975(99) 01294-1.

[15] C.C.S. Lim, F. Cuculi, W.J. van Gaal, L. Testa, J.R. Arnold, T. Karamitsos, J.M. Francis, J.E. Digby, C. Antoniades, R.K. Kharbanda, S. Neubauer, S. Westaby, A.P. Banning, Early diagnosis of perioperative myocardial infarction after coronary bypass grafting: a study using biomarkers and cardiac magnetic resonance imaging, Ann. Thoracic Sur. 92 (2011) 2046-2053, https://doi.org/10.1016/j.athoracsur. 2011.05.019.

[16] F. Onorati, M. De Feo, P. Mastroroberto, L. Cristodoro, F. Pezzo, A. Renzulli,
M. Cotrufo, Determinants and prognosis of myocardial damage after coronary artery bypass grafting, Ann. Thor. Sur. 79 (2005) 837-845, https://doi.org/10.1016/ j.athoracsur.2004.07.060.

[17] A.A. Peivandi, M. Dahm, U.T. Opfermann, D. Peetz, F. Doerr, A. Loos, H. Oelert Comparison of cardiac troponin i versus $t$ and creatine kinase $\mathrm{mb}$ after coronary artery bypass grafting in patients with and without perioperative myocardial infarction, Herz 29 (2004) 658-664, https://doi.org/10.1007/s00059-004-2543-y.

[18] C. Proust-Lima, V. Philipps, B. Liquet, Estimation of extended mixed models using latent classes and latent processes: the r package lcmm, J. Stat. Softw. 78 (2017) 1-56, https://doi.org/10.18637/jss.v078.i02.

[19] N.M. Laird, J.H. Ware, Random-effects models for longitudinal data, Biometrics. 38 (1982) 963-974.

[20] G. Verbeke, G. Molenberghs, Linear Mixed Models for Longitudinal Data, Springer Science \& Business Media, New York, 2009.

[21] B. Muthén, K. Shedden, Finite mixture modeling with mixture outcomes using the EM algorithm, Biometrics 55 (1999) 463-469, https://doi.org/10.1111/j.0006341X.1999.00463.x.

[22] F.E. Harrell, Regression modeling strategies: with applications to linear models, logistic and ordinal regression, and survival analysis, Second ed., Springer, New York, 2015.

[23] R. Core, R. Team, A Language and Environment for Statistical Computing, R Foundation for Statistical Computing, Vienna, Austria, 2019.

[24] G. Schwarz, Estimating the dimension of a model, Ann. Statist. 6 (1978) 461-464, https://doi.org/10.1214/aos/1176344136.

[25] K.L. Nylund, T. Asparouhov, B.O. Muthén, Deciding on the number of classes in latent class analysis and growth mixture modeling: a monte carlo simulation study, Struct. Eq. Model.: A Multidiscipl. J. 14 (2007) 535-569, https://doi.org/10.1080/ 10705510701575396.

[26] M. Kuhn, Building predictive models in R using the caret package, J. Stat. Softw. 28 (2008) 1-26, https://doi.org/10.18637/jss.v028.i05.

[27] W.J. Youden, Index for rating diagnostic tests, Cancer 3 (1950) 32-35, https://doi. org/10.1002/1097-0142(1950) 3:1 <32::AID-CNCR2820030106>3.0.CO;2-3.

[28] R.E. Kass, A.E. Raftery, Bayes factors, J. Am. Stat. Assoc. 90 (1995) 773-795, https://doi.org/10.1080/01621459.1995.10476572.

[29] H.A. Katus, A. Remppis, T. Scheffold, K.W. Diederich, W. Kuebler, Intracellular compartmentation of cardiac troponin $\mathrm{T}$ and its release kinetics in patients with reperfused and nonreperfused myocardial infarction, Am. J. Cardiol. 67 (1991) 1360-1367, https://doi.org/10.1016/0002-9149(91)90466-X.

[30] A.L. Baggish, T.E. MacGillivray, W. Hoffman, J.B. Newell, K.B. Lewandrowski, E. Lee-Lewandrowski, S. Anwaruddin, U. Siebert, J.L. Januzzi, Postoperative troponin-T predicts prolonged intensive care unit length of stay following cardiac surgery, Crit. Care Med. 32 (2004) 1866-1871, https://doi.org/10.1097/01.ccm. 0000139692.19371 .7 c.

[31] B. Gahl, V. Göber, A. Odutayo, H.T. Tevaearai Stahel, B.R. da Costa, S.M. Jakob, G.M. Fiedler, O. Chan, T.P. Carrel, P. Jüni, Prognostic value of early postoperative troponin $\mathrm{T}$ in patients undergoing coronary artery bypass grafting, J. Am. Heart Assoc. 7 (2018), https://doi.org/10.1161/JAHA.117.007743.

[32] V. Göber, A. Hohl, B. Gahl, F. Dick, V. Eigenmann, T.P. Carrel, H.T. Tevaearai, Early troponin $\mathrm{T}$ and prediction of potentially correctable in-hospital complications after coronary artery bypass grafting surgery, PLoS ONE 8 (2013) e74241, , https://doi. org /10.1371/journal.pone.0074241.

[33] D.J. Bauer, P.J. Curran, distributional assumptions of growth mixture models: implications for overextraction of latent trajectory classes, Psychol. Methods 8 (2003) 338-363, https://doi.org/10.1037/1082-989X.8.3.338. 